\title{
Preparation of a Novel Infrared Photoinitiator and Kinetic Monitoring of Photopolymerization by Real Time FT-IR Spectroscopy
}

\author{
Bin LI, ${ }^{\dagger}$ Shihai ZHANG, Liming TANG, and Qixiang ZHoU \\ Department of Chemical Engineering, Materials Research Center, \\ Tsinghua University, Beijing 100084, People's Republic of China
}

(Received October 10, 2000; Accepted December 25, 2000)

\begin{abstract}
In this paper, a novel cationic cyanine dye-borate complex, 1,3,3,1',3',3'-hexamethyl-11-chloro- 10,12propylenetricarbocyanine triphenylbutylborate was prepared and used as the photoinitiator in infrared laser-induced photopolymerization of acrylates. It had a maximum electron absorption at $786 \mathrm{~nm}$, which matched well with the output wavelength of the adopted infrared laser diode, with a maximum molar extinction coefficient of $1.4 \times 10^{5} \mathrm{~L} \mathrm{~mol}^{-1} \mathrm{~cm}^{-1}$ in chloroform solution. Under the irradiation of infrared laser the polymeric samples based on phthalicdiglycol diacrylate (PDDA), binder, photoinitiator and solvent polymerized and the polymerizing process was monitored through Real Time FT-IR spectroscopy (RTFT-IR). The double bond conversion was determined from the reduction of the absorption of acrylate monomer at $1635 \mathrm{~cm}^{-1}$ and $1620 \mathrm{~cm}^{-1}\left(\mathrm{CH}_{2}=\mathrm{CH}\right.$ strentching) in FT-IR spectra during laser irradiation. As the concentration of photoinitiator rose, the polymerization rate $(\mathrm{Rp})$ increased rapidly but then decreased when the concentration reached a critical value. $\mathrm{Rp}$ and the ultimate double bond conversion of sample increased when the infrared laser power was enhanced, whereas they fell greatly as the thickness of the polymeric sample layer increased.
\end{abstract}

KEY WORDS Infrared Laser / Photoinitiator / Phthalicdiglycol Diacrylate / Real Time / FT-IR /

It is well known that photopolymerization has many distinct virtues such as rapid reaction rate, low energy or space requirements for processing and little pollution to the environment. ${ }^{1}$ In the past decades study on photopolymerization induced by UV irradiation was well developed and traditional UV light sources were widely used for various industrial applications, e.g., photosensitive polymer materials including photoresists, photocurable varnishes, fast-drying inks, photocurable adhesives and information-recording media. But for the use of imaging such as in offset process, there must be a stage where multiple pieces of paper become film or negative pages when using traditional UV source. On the other hand, such a cost- and time-consuming process can be avoided by the use of laser sources. An image from the computer can be directly written on the pre-sensitized plates by the scanning of laser beam (such a technology was called "Direct-To-Plate" or "Computer-To-Plate" (CTP) in industry). ${ }^{2-6}$ So savings in costs and improvements in efficiency can be brought through CTP. Infrared laser diode is small, compact and easy to operate, so it's a suitable laser source to be used in this technology. But the most superiority of it lies in its cheap price. As soon as the commodity of infrared laser diode became available, it was regarded highly competitive to be utilized for achieving CTP.

However, there were few photoinitiators matching well with the wavelength of infrared light, which strongly impeded the development of infrared laserinduced polymerization. In the past years there were a few investigations on the synthesis of infrared photoinitiators but they were all reported in patents. ${ }^{7-12}$ There are no commercial infrared photoinitiators available at present.
The kinetics study of photopolymerization has been the main subject of researches on photopolymerization all the while. Many traditional discrete methods such as IR spectroscopy ${ }^{13}$ and FT-IR photoacoustic spectroscopy ${ }^{14}$ or continuous measuring like in methods based on dilatometry, ${ }^{15}$ differential photocalorimetry ${ }^{16}$ and laser interferometry ${ }^{17}$ have been developed. However, these methods can only monitor the photopolymerization in large time scale, that is, the one that proceeds slowly. As for photopolymerization induced by laser with high energy density, since the reaction takes place so rapidly that it can be finished within a fraction of second, the methods above become unsuitable. In the past years there were a few novel analytical methods favorable for ultra-fast photopolymerizations appeared, including Real Time FT-IR spectroscopy (RTFT-IR), ${ }^{18-23}$ Real Time Fluorescence Probe methodology (RTFP) ${ }^{24}$ and Real Time Attenuated Total Reflectance FT-IR spectroscopy (RTATR). ${ }^{25}$ These new methods endued the study of fast photopolymerization fresh sight. Among them RTFT-IR provided us a convenient way to monitor the residual double bonds in the polymerizing system directly and so it was employed in many studies.

In this article, we prepared a kind of cationic cyanine dye-borate complex (CBC), 1,3,3,1',3',3'-hexamethyl-11chloro-10,12-propylenetricarbocyanine triphenylbutylborate, which was employed as the photoinitiator for the infrared laser-induced polymerization of phthalic diglycol diacrylate (PDDA). The influence of polymerization parameters including concentration of photoinitiator, laser energy and thickness of the sample layer on the kinetics of photopolymerization of PDDA was studied through RTFT-IR.

\footnotetext{
${ }^{\dagger}$ To whom correspondence should be addressed.
} 


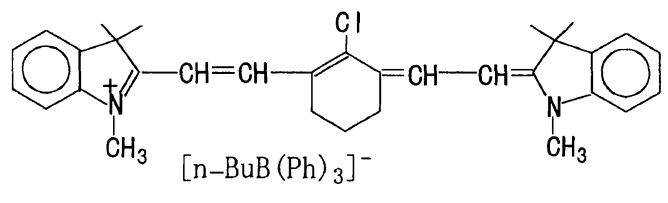

$\mathrm{CBC}$

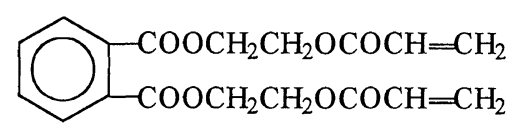

PDDA

Figure 1. Chemical formula of the photoinitiator and monomer.

\section{EXPERIMENTAL}

\section{Materials}

Triphenylborane was purchased from Aldrich Chem. Co. and used as received. Phthalic diglycol diacrylate (PDDA) (Figure 1) was a largess from Dongfang Chemical Engineering Factory, Beijing. It was used without removing of the stabilizers because it seemed that this procedure resulted in little instability in the polymerizing system. The copolymer of acrylic acid (AA), methyl methylacrylate (MMA), styrene (St) and butyl acrylate (BA) (AA/MMA/St/BA = 20/45/10/25 (wt ratio)) was used as the binder in the polymerizing system in order to improve the adhesion of polymeric sample to the substrate. All the other compounds were of analytically pure grade and were used without further purification.

\section{Synthesis of the Photoinitiator}

Cationic Cyanine Dye. The cationic cyanine dye 1,3,3,1', 3', 3'-hexamethyl-11-chloro-10,12- propylenetricarbocyanine iodide was prepared according to the procedure reported in ref $26 . \mathrm{Mp} 258-259^{\circ} \mathrm{C}$. Anal. Calcd. for $\mathrm{C}_{32} \mathrm{H}_{36} \mathrm{~N}_{2}$ ClI: C, 62.90; H, 5.90; N, 4.59. Found: C, 62.68; H, 6.00; N, 4.55. IR (KBr): 1610, 1550, 1510, 1450, $1390,770 \mathrm{~cm}^{-1} .{ }^{1} \mathrm{H}$ NMR (DMSO): $1.55-2.00(\mathrm{~s}, 12 \mathrm{H})$, $2.58-3.00(\mathrm{~m}, 6 \mathrm{H}), 3.20-3.80(\mathrm{~s}, 6 \mathrm{H}), 6.16-6.55(\mathrm{~m}$, $4 \mathrm{H}), 7.13-8.48(\mathrm{~m}, 8 \mathrm{H})$. The maximum absorption wavelength, $\lambda_{\max }$, for the dye in methanol is $774 \mathrm{~nm}$ with a maximum molar extinction coefficient, $\varepsilon_{\max }$, of 2.7 $\times 10^{5} \mathrm{~L} \mathrm{~mol}^{-1} \mathrm{~cm}^{-1}$

Tetramethylammonium $n$-Butyltriphenylborate. The triphenylborane was dissolved in $100 \mathrm{~mL}$ dry benzene (1 M) under nitrogen atmosphere. The flask was placed in a cool water bath and $n-\mathrm{BuLi}$ (1.1 equiv of theoretical) was added via syringe while stirring strongly. A white precipitate soon formed after addition was started. Stirring was continued for about $45-60 \mathrm{~min}$. The mixture was diluted with $50 \mathrm{~mL}$ hexane and filtered, then washed with hexane. This resultant lithium $n$ butyltriphenylborate salt was slightly air-unstable. The white powder was dissolved in about $200 \mathrm{~mL}$ deionized water and the aqueous solution of tetramethylammonium chloride (1.2 equiv of theoretical in $200 \mathrm{~mL}$ ) was added into it with vigorous stirring. A thick white precipitate immediately formed. This aqueous mixture was stirred for $30 \mathrm{~min}$ at room temperature and then filtered. The collected white solid was washed with deionized water and dried it to get the product. $\mathrm{Mp} 248-250^{\circ} \mathrm{C}$. Anal. Calcd. for $\mathrm{C}_{26} \mathrm{H}_{36} \mathrm{NB}$ : C, 83.87; H, 9.68; N, 3.76.
Found: C, 83.58; H, 9.43; N, 3.87.

Cationic Cyanine Dye-Borate Complex (Photoinitiator). A very fine suspension of the tetramethylammonium $n$-butyltriphenylborate $\left(0.1 \mathrm{~g} \mathrm{~mL}^{-1}\right)$ in methanol was made under vigorous stirring. The flask was protected from light by wrapping it with aluminum foil. The temperature of the reacting system was kept at around $50^{\circ} \mathrm{C}$ by using a water bath. Then 1 equiv of the above cationic cyanine dye was added into the flask while stirring. After stirring for 30 min the mixture was cooled to room temperature, then diluted with 10 volumes of ice water. The resultant solid was filtered and washed with deionized water until the washing was colorless. The solid was suction-filtered to dryness and the so-obtained photoinitiator compound was completely dried at room temperature in a vacuum drying oven to get an olive powder product. $\mathrm{Mp} 140^{\circ} \mathrm{C}$, Decomposing temperature $178^{\circ} \mathrm{C}$. Anal. Calcd. For $\mathrm{C}_{54} \mathrm{H}_{60} \mathrm{~N}_{2}$ ClB: C, 82.81; H, 7.67; N, 3.58. Found: C, 81.99; H, 7.68; N, 3.22.

\section{Sample Preparation and Photopolymerization Condi- tions}

To prepare the sample for photopolymerization the photoinitiator, PDDA monomer and binder were first dissolved in butanone. For all of the samples in this article the concentration of PDDA and binder was set constant with monomer $v s$. binder being $1: 1$ (wt/wt). The concentration of PDDA was $0.7 \mathrm{~mol} \mathrm{~L}^{-1}$. The mixture was purged with nitrogen for 15 min while stirring to exclude the oxygen. A drop of the mixture was applied as a uniform layer on a $\mathrm{NaCl}$ crystal tablet. The thickness of the layer was controlled by one or more frames made by aluminum foil, which was $20 \mu \mathrm{m}$ of thickness. The samples were covered with another $\mathrm{NaCl}$ tablet and sealed the sides around the two tablets with inert silicone grease in order to prevent the diffusion of atmospheric oxygen into the polymeric layer.

The FT-IR spectra were obtained with a NICOLET 560 FT-IR spectrometer at a resolution of $8 \mathrm{~cm}^{-1}$. The in situ spectra were taken every $10 \mathrm{~s}$ with a scan speed of 1 $\mathrm{s}$ scan $^{-1}$. The sample for photopolymerization was fixed in the FT-IR sample chamber to ensure the analyzing area not changed during the experimental procedure. The infrared laser source was an infrared laser diode purchased from Institute of Semiconductors, Chinese Academy of Sciences, which had output wavelength at $796 \mathrm{~nm}$. The infrared laser beam was imported to the chamber through an optical fiber. The output laser beam was adjusted to suitable size in favor of the choice of analyzing area during FT-IR measurement. Energy output of the laser beam at the exporting port was determined with LPE-1 energometor (Institute of Physics, Chinese Academy of Sciences). The sample polymerized under the irradiation of laser beam in the FT-IR sample chamber with its IR spectra being measured instantaneously. In this way RTFT-IR was realized. Figure 2 schematically describes the experimental setup in order to expose the sample to the infrared laser beam, which induces the photopolymerization, and the analytical IR beam, which monitors the drop of the absorbance of the reactive group, at the same time.

The absorbance of acrylate monomer at the doublepeak of $1635 \mathrm{~cm}^{-1}$ and $1620 \mathrm{~cm}^{-1} \quad\left(\mathrm{CH}_{2}=\mathrm{CH}\right.$ 


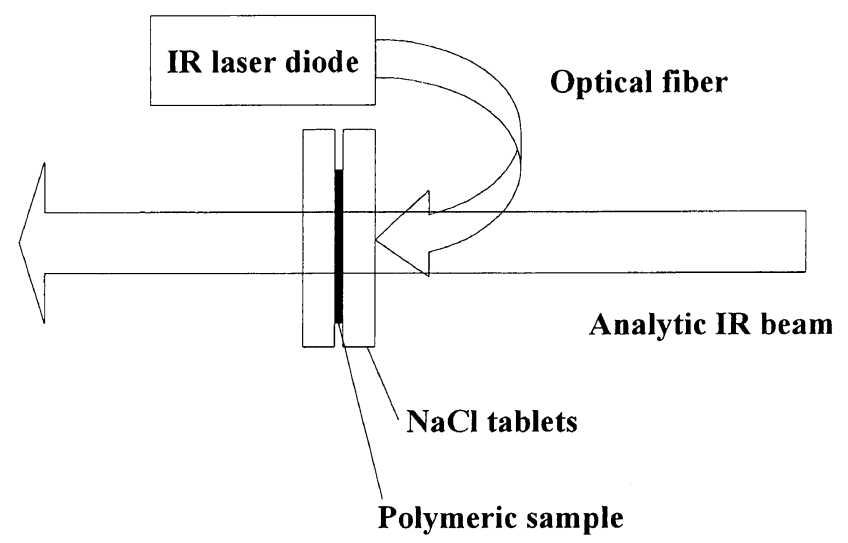

Figure 2. Schematic experimental setup for photopolymerization kinetics study by RTFT-IR spectroscopy.

strentching) was used for calculating the conversion of double bond during photopolymerization. The conversion of acrylic double bond $(\gamma)$ was determined from the change of the absorbance before and after infrared laser irradiation according to

$$
\gamma=\left(A_{0}-A_{1}\right) / A_{0} \times 100 \%
$$

where $A_{0}$ and $A_{1}$ were the absorbance at $1635 \mathrm{~cm}^{-1}$ and $1620 \mathrm{~cm}^{-1}$ before and after infrared laser irradiation, respectively.

The rate of polymerization $(\mathrm{Rp})$ was obtained from the slope $(\gamma / t)$ of the linear part of the time-conversion curve below a $10 \%$ of conversion according to eq 2 ,

$$
\mathrm{Rp}=[\mathrm{M}](\Delta \gamma / \Delta t)
$$

where $[\mathrm{M}]$ is the molar concentration of PDDA monomer before laser irradiation. Units: Rp, $\mathrm{mol} \mathrm{L}^{-1} \mathrm{~s}^{-1}$; $[\mathrm{M}]$, mol $\mathrm{L}^{-1} ; t, \mathrm{~s}$.

\section{Electron Spinning Resonance (ESR)}

ESR was performed in Bruker ER $200 \mathrm{D}$-SRC spectrometer with 2-Methyl-2-Nitroso-Propane (MNP) as a radical capturing agent. $\mathrm{CBC}$ and $\mathrm{MNP}$ were dissolved in toluene to form a saturated solution. The solution was purged with nitrogen for 10 min to get rid off the oxygen, then it was irradiated under the infrared laser for $5 \mathrm{~min}$ at a laser power density of $7.0 \mathrm{~mW} \mathrm{~cm} \mathrm{~cm}^{-2}$. ESR spectrum was collected from this irradiated solution with central magnetic field intensity of $347 \mathrm{mT}$ and scanning range of $4 \mathrm{mT}$ at room temperature.

\section{RESULTS AND DISCUSSION}

\section{Synthesis of the Photoinitiator}

Synthesis of the photoinitiator is described in Scheme 1. The lithium salt of $n$-butyltriphenylborate was first prepared from triphenylborane and $n$-butyllithium. Since this lithium salt is a little unstable in air atmosphere, it further reacted with tetramethylammonium chloride to get a borate salt of tetramethylammonium, which was very stable and could be stored for more than one year. Then this borate salt was treated with the cationic cyanine dye through a kind of ion-exchange reaction, and eventually the cationic cyanine dye-borate complex (photoinitiator) was obtained.

The maximum absorption wavelength for the photoinitiator in chloroform is $786 \mathrm{~nm}$ with a maximum molar extinction coefficient of $1.4 \times 10^{5} \mathrm{~L} \mathrm{~mol}^{-1} \mathrm{~cm}^{-1}$. Since the output wavelength of the infrared laser employed is $796 \mathrm{~nm}$, the absorbance of the photoinitiator matches it well.

There have been many studies on the photophysics of reactions of carbocyanine alkyltriphenylborate salts up to present. ${ }^{27-29}$ They have shown that under the irradiation there is an intramolecular electron transfer from borate, the anionic part, to the triplet state of the cyanine, the cationic part of the salt. This process leads to the formation of alkyl radicals, which are responsible for the initiation of photopolymerization. The major difference between CBC in this paper and those absorbed in the visible region and used by $\mathrm{S}$. Chatterjee et al. ${ }^{27,29}$ is that the former has more conjugated double bond number, so is sensitive to light with longer wavelength. It is reasonable to assume the $\mathrm{CBC}$ would also undertake the same intra-ion-pair electron transfer process (Scheme 2) under the irradiation of infrared laser beam because of the

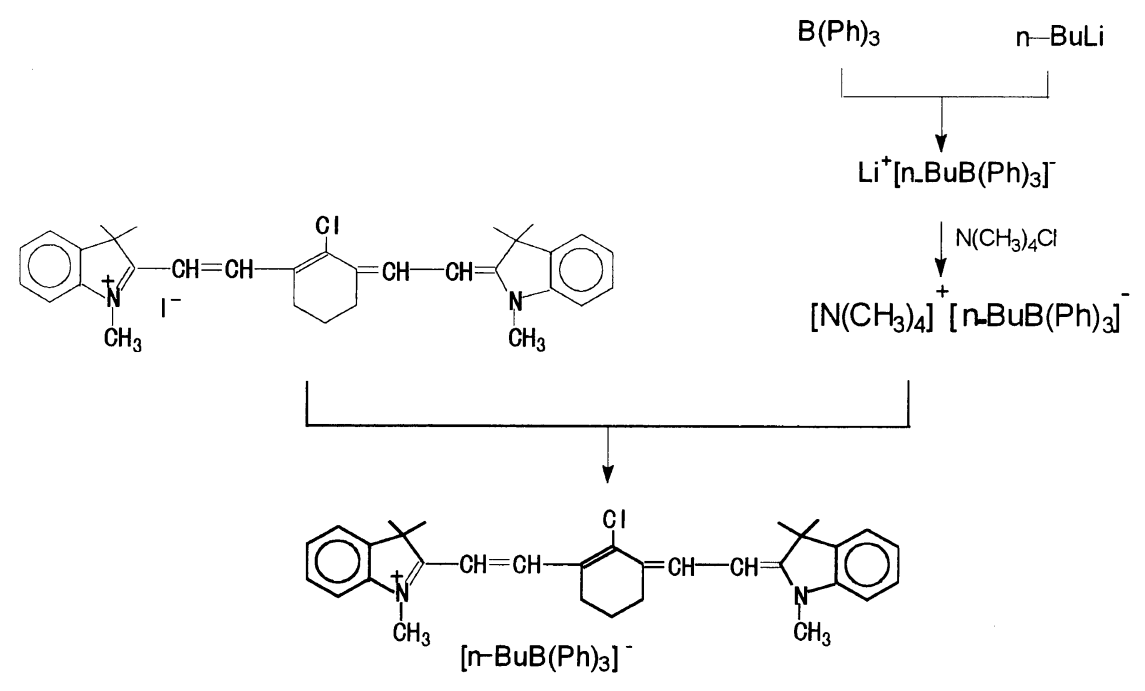

Scheme 1. Synthesis of the photoinitiator. 


$$
\begin{aligned}
& \mathrm{Dye}^{+}\left[\mathrm{n} \_\mathrm{BuBPh} 3\right]^{-} \stackrel{\mathrm{h} v}{\longrightarrow} \text { Dye } \cdot+\left[\mathrm{n}_{-} \mathrm{BuBPh}_{3}\right] \cdot \\
& \stackrel{\mathrm{BPh}}{\longrightarrow}+\mathrm{n} \_\mathrm{Bu} \cdot \stackrel{\text { PDDA }}{\longrightarrow} \text { Polymer }
\end{aligned}
$$

Scheme 2. Schematic illustration of photolysis and photoinitiation of the photoinitiator.

similarity in their chemical structures. The resonance peaks shown in the ESR spectrum of CBC after irradiation of infrared laser (Figure 3 ) indicated that $n$-butyl radicals had been formed.

\section{Photopolymerization of PDDA}

Under infrared laser irradiation the photoinitiator in the polymeric sample absorbed photons and began to photolyze. Then the so-formed $n$-butyl radicals initiated

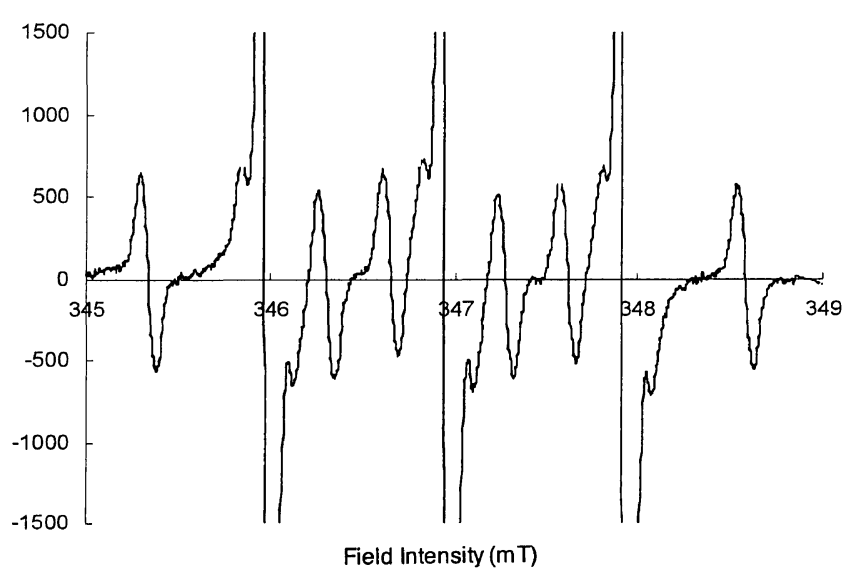

Figure 3. ESR spectrum of $\mathrm{CBC}$ after irradiation of infrared laser (Laser power density: $7.0 \mathrm{~mW} \mathrm{~cm}{ }^{-2}$, laser irradiation duration: $300 \mathrm{~s})$. the polymerization of PDDA monomer. Since the FT-IR spectra of the sample were obtained at the same time when the photopolymerization was proceeding, the drop of absorbance at the double-peak of $1635 \mathrm{~cm}^{-1}$ and 1620 $\mathrm{cm}^{-1}\left(\mathrm{CH}_{2}=\mathrm{CH}\right.$ strentching $)$ or the single-peak at 810 $\mathrm{cm}^{-1}\left(\mathrm{CH}_{2}=\mathrm{CH}\right.$ twisting) exactly monitored the decrease of double bonds in the sample. The absorbance of photoinitiator at $793 \mathrm{~cm}^{-1}$ was also seen clearly reducing during irradiation of laser. Generally the change of absorbance at $1635 \mathrm{~cm}^{-1}$ and $1620 \mathrm{~cm}^{-1}$ or at $810 \mathrm{~cm}^{-1}$ could be used for calculating the percentage conversion of double bond. But since absorbance peak of the monomer at $810 \mathrm{~cm}^{-1}$ overlapped partially with that of the photoinitiator at $793 \mathrm{~cm}^{-1}$, the absorbance at $1635 \mathrm{~cm}^{-1}$ and $1620 \mathrm{~cm}^{-1}$ was employed for determining the double bond conversion.

Figure 4 shows the spectra for a sample with photoinitiator concentration of $2.5 \%$ and irradiated under a laser energy density of $17.0 \mathrm{~mW} \mathrm{~cm}{ }^{-2}$ for different time. It is clearly that the double bond decreased rapidly with the laser irradiation, then the polymerization rate slowed to reach a plateau. The double bond conversion reached around $65 \%$ after irradiated for $10 \mathrm{~min}$. The exposed area changed to a fine film and could not be dissolved in solvents any more. This means that the sample polymerized and cured effectively as a result of infrared laser irradiation.

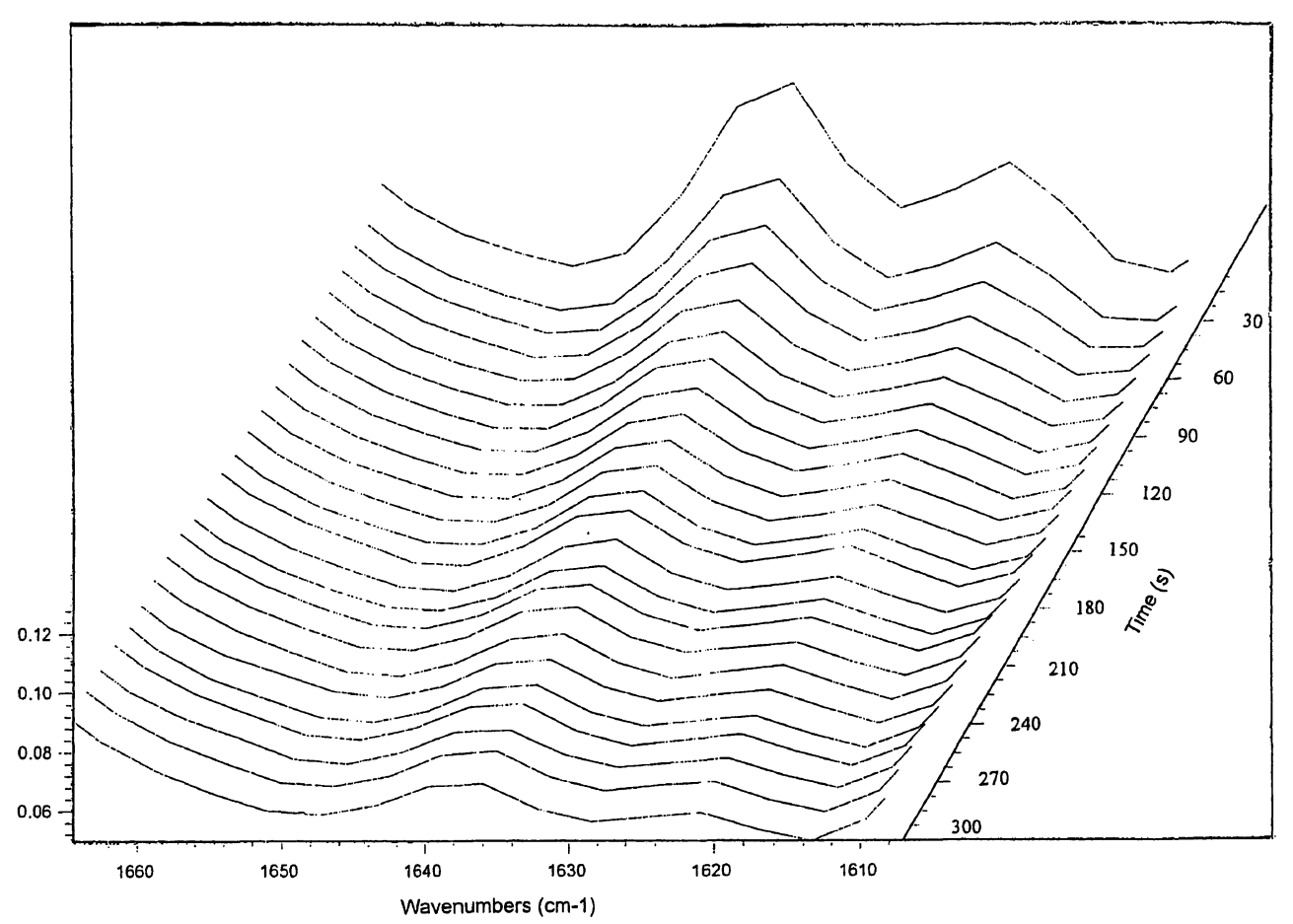

Figure 4. FT-IR spectra for the photopolymerization sample at different time (Concentration of PDDA: 0.7 mol L ${ }^{-1}$, laser power density: $17.0 \mathrm{~mW} \mathrm{~cm}{ }^{-2}$, CBC content: $2.5 \mathrm{wt} \%$, sample thickness: $20 \mu \mathrm{m}$ ). 


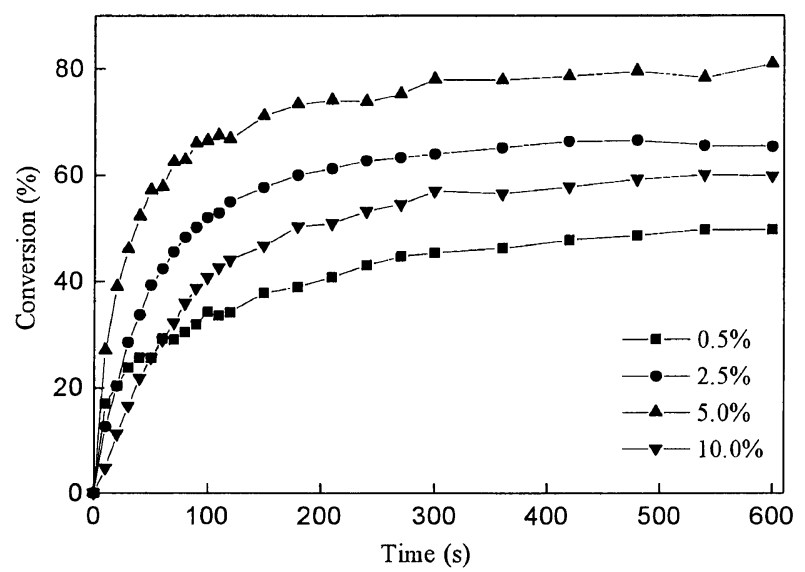

Figure 5. Double bond conversion of samples with different concentration of photoinitiator (Concentration of PDDA: $0.7 \mathrm{~mol} \mathrm{~L}^{-1}$, laser power density: $17.0 \mathrm{~mW} \mathrm{~cm}^{-2}$, sample thickness: $20 \mu \mathrm{m}$ ).

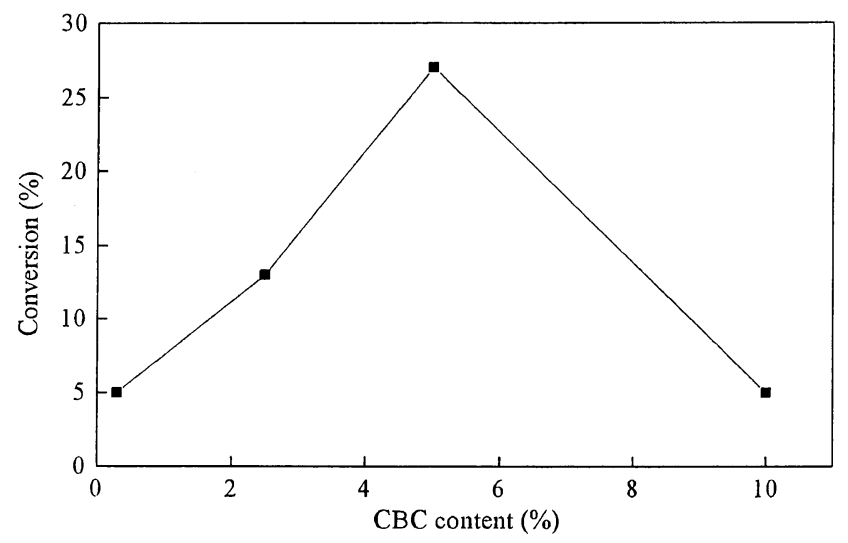

Figure 6. Influence of $\mathrm{CBC}$ content on the double bond conversion of PDDA with $10 \mathrm{~s}$ of laser irradiation (Concentration of PDDA: $0.7 \mathrm{~mol} \mathrm{~L}^{-1}$, laser power density: $17.0 \mathrm{~mW} \mathrm{~cm}^{-2}$, sample thickness: $20 \mu \mathrm{m})$.

\section{Influence of Concentration of Photoinitiator}

Figure 5 shows the polymerization curves of samples with different concentration of photoinitiator. The CBC content (the weight ratio of CBC vs. PDDA) in the polymeric mixture played a significant role for the polymerization rate and double bond conversion. As the concentration of CBC rose from $0.5 \%$ to $5 \%$, the rate of polymerization increased greatly. However, further increasing concentration of photoinitiator did not improve Rp correspondingly. On the other hand, Rp decreased when the concentration of photoinitiator was above 5\%. Figure 6 depicts the relationship between the double bond conversion at the end of $10 \mathrm{~s}$ of laser irradiation and concentration of CBC.

Such an unusual phenomenon may be attributed to the internal filter effect of the photoinitiator ${ }^{20}$ which prevents the infrared light from penetrating into the deep part of the high absorbing layer. It's also possible that when the concentration of photoinitiator is so high that too many radicals are formed at the same time, the coupling of these radicals results in the decrease of initiation efficiency. So there is an optimum value for the concentration of photoinitiator in the polymerizing system.

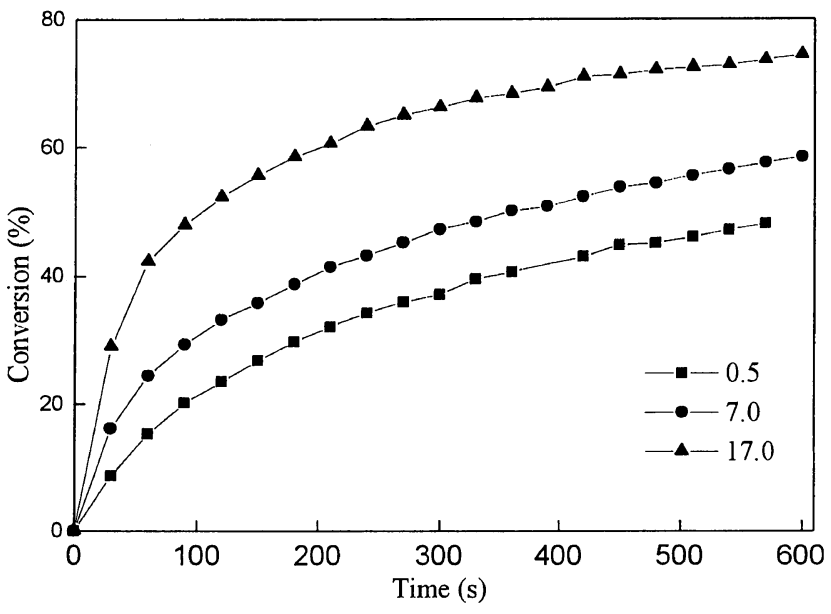

Figure 7. Double bond conversion of samples under irradiation of different laser power density (Concentration of PDDA: $0.7 \mathrm{~mol}$ $\mathrm{L}^{-1}$, CBC content: $5.0 \mathrm{wt} \%$, sample thickness: $40 \mu \mathrm{m}$, laser power

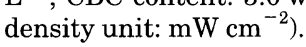

\section{Influence of Laser Power}

As what is depicted in Figure 7, Rp increased when the power of infrared laser was enhanced. The light intensity of the laser $\left(I_{0}\right)$ was not measured directly in the experiments. But since light intensity was proportional to laser power density $(W)$, it's reasonable to use the value of laser power density for the determination of polymerization kinetics. For typical photopolymerization in which the termination step is by di-radical termination mode, there is a kinetic relationship as eq $3 .^{30}$

$$
\mathrm{Rp}=k_{\mathrm{p}}[\mathrm{M}]\left(\phi \varepsilon I_{0}[\mathrm{Ini}] / k_{\mathrm{t}}\right)^{0.5}
$$

where $k_{\mathrm{p}}$ and $k_{\mathrm{t}}$ are propagation rate constant and termination rate constant, respectively. $[\mathrm{M}]$ and [Ini] are the concentration of monomer and photoinitiator, respectively. Units: $\mathrm{Rp}, \mathrm{mol} \mathrm{L}{ }^{-1} \mathrm{~s}^{-1} ;[\mathrm{M}]$ and [Ini], $\mathrm{mol} \mathrm{L}^{-1} ; k_{\mathrm{p}}$ and $k_{\mathrm{t}}, \mathrm{L} \mathrm{mol}^{-1} \mathrm{~s}^{-1} ; \varepsilon, \mathrm{s}^{-1}$.

When the other parameters are set constant, $\mathrm{Rp}$ is proportional to the square root of light intensity, $I_{0}^{0.5}$, and so proportional to $W^{0.5}$. If the logarithm of both sides of eq 3 is taken and $W$ is used, there should be

$$
\log \operatorname{Rp} \propto 0.5 \log W
$$

So there must be a linear correlation between $\log \mathrm{Rp}$ and $\log W$ with a slope of 0.5 . To testify this equation, a figure of $\log R p v s . \log W$ is depicted in Figure 8. What we can see from this figure approves of it.

It can be seen that the ultimate double bond conversion of sample irradiated under higher laser power was also larger than that under lower laser power. For the sample irradiated with laser power density of $17.0 \mathrm{~mW}$ $\mathrm{cm}^{-2}$, the double bond conversion of sample after irradiated for $10 \mathrm{~min}$ could reach $74 \%$, while for that with laser power density of $0.5 \mathrm{~mW} \mathrm{~cm} \mathrm{~cm}^{-2}$ only $49 \%$. This is also attributed to the internal filter effect of photoinitiator.

\section{Influence of Thickness of the Samples}

The FT-IR spectra of samples with different thickness were shown in Figure 9. As the thickness of the polymeric sample layer increased from $20 \mu \mathrm{m}$ to $80 \mu \mathrm{m}$, the 


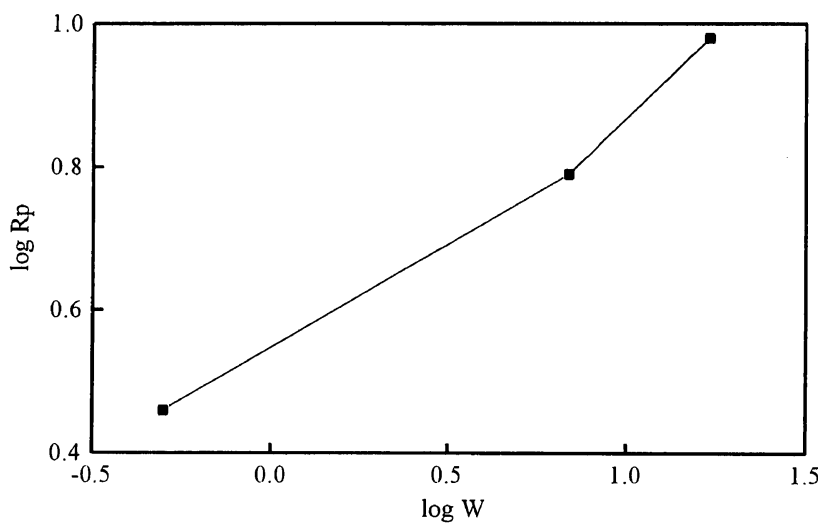

Figure 8. The relationship between $\log \mathrm{Rp}$ and $\log W$ (Concentration of PDDA: $0.7 \mathrm{~mol} \mathrm{~L}^{-1}, \mathrm{CBC}$ content: $5.0 \mathrm{wt} \%$, sample thickness: $40 \mu \mathrm{m}$ ).

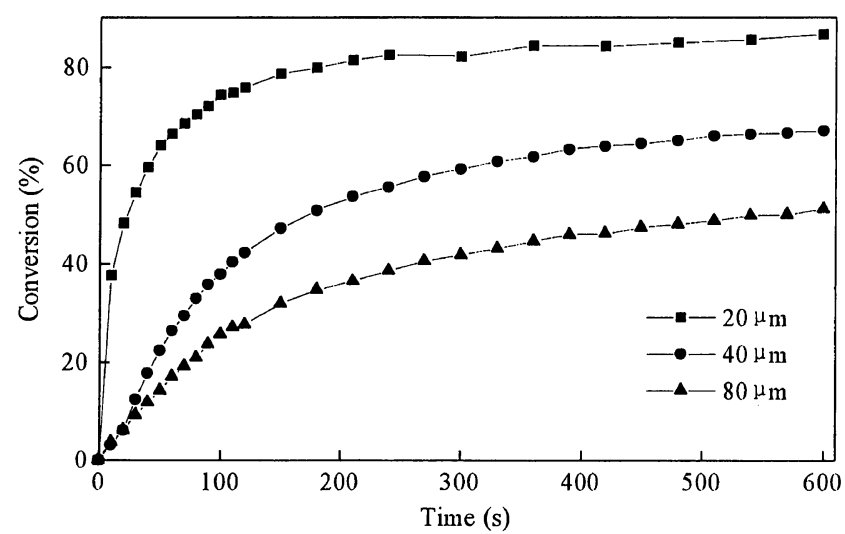

Figure 9. Double bond conversion of samples with different thickness (Concentration of PDDA: $0.7 \mathrm{~mol} \mathrm{~L}^{-1}$, laser power density: $17.0 \mathrm{~mW} \mathrm{~cm}{ }^{-2}$, CBC content: $5.0 \mathrm{wt} \%$ ).

rate of polymerization fell significantly. According to Lambert-Beer Law, the light traversing through a layer of absorbing media weakens greatly along the direction of thickness. When thickness of the sample increases it is possible that the underside of the layer undergoes no light irradiation and so no polymerization occurs. But the FT-IR spectrum obtained is still for the whole layer. Then there must be a lower value for the conversion calculated (apparent conversion) compared with its actual value and it is the same case for the measurement of $R p$ (apparent $R p$ ).

Also it's clear that the final double bond conversion for the thicker sample is lower than that of the thinner one, which shows the result of internal filter effect of the photoinitiator again.

\section{CONCLUSION}

A novel cationic cyanine dye-borate complex was prepared through ion-exchange reaction between cationic cyanine dye and tetramethylammonium $n$ butyltriphenylborate. Its absorbance matched the output wavelength of the infrared laser used in this article well and was employed as the photoinitiator for the infrared laser-induced photopolymerization. The photopolymerization of PDDA was successfully monitored through Real Time FT-IR spectroscopy (RTFT-IR).

As the concentration of photoinitiator rose, the polymerization rate $(\mathrm{Rp})$ and double bond conversion increased considerably. However, they decreased when the concentration of photoinitiator exceeded a critical value as a result of the internal filter effect of photoinitiator. The coupling of radicals at high concentration of photoinitiator, which results in decreasing of initiation efficiency, may also account for it.

Rp increased when the infrared laser power was enhanced. The ultimate double bond conversion of sample irradiated under higher laser power was larger than that under lower laser power. The relationship between $\mathrm{Rp}$ and laser power revealed that there was a correlation of $\mathrm{Rp} v s$. square root of laser power.

As the thickness of the polymeric sample layer increased, Rp fell significantly. The final double bond conversion for the thicker sample is also lower than the thinner one, which may also be attributed to internal filter effect of the photoinitiator.

Acknowledgment. The authors of this paper appreciate the great help of Prof. Kunhua Wang of Tsinghua University in devising and adjusting the RTFT-IR setup.

\section{REFERENCES}

1. C. Decker and J. P Fouassier, in "Lasers in Polymer Science and Technology: Applications (III)", J. P. Fouassier and J. F. Rabek, Ed., CRC Press, Boca Raton, 1989, p 1.

2. P. R. West and J. A. Gurney, U. S. Patent 5821030 (Oct. 13, 1998).

3. H. P. Herting and R. M. Goodman, "Proceedings of the Technical Association of the Graphic Arts, TAGA 1998", TAGA, Rochester, New York, N.Y., p 312.

4. J. Van Hunsel, M. Van Damme, J. Vermeersch, A. Elsasser and D. Seeley, "Proceedings of the Technical Association of the Graphic Arts, TAGA 1998," TAGA, Rochester, New York, N.Y., p 395.

5. G. Guidoni, Canadian Packaging, 52(5), 2 (1999).

6. B. Sims, Presstime, 21(7), 73 (1999).

7. J. A. Bonham, M. A. Rossman, and R. J. Grant, Eur. Patent 0 359430 A 2 (Mar. 21, 1990).

8. N. F. Haley and S. L. Corbiere, U. S. Patent 5466557 (Nov. 14, 1995).

9. T. Yamamoto, K. Otani, and H. Yoshida, J. Patent 0977836 (Mar. 25, 1997)

10. T. Kuroki, T. Maebashi, and S. Matsumoto, J. Patent 09197 668 (Jul. 31, 1997)

11. T. Iwai, T. Okui, and H. Komano, J. Patent 09244236 (Sep. 19, 1997).

12. Y. Okamoto, S. Kondo, and T. Ukai, U. S. Patent 5385807 (Jan. 31, 1995).

13. C. Decker and T. Bendaikha, Eur. Polym. J., 20, 753 (1984).

14. R. D. Small, J. A. Ors, and B. S. Royce, ACS Symp. Ser., 242, 325 (1984).

15. D. R. Pemberton and A. F. Johnson, Polymer, 25, 529 (1984).

16. J. G. Kloosterboer and G. F. C. M. Lijten, Polymer, 28, 1149 (1987).

17. C. Decker, in "Radiation Curing of Polymers", D. Randell, Ed., Royal Society Chemistry, London, 1987, 64, p 16.

18. C. Decker and K. Moussa, Makromol. Chem., 189, 2381 (1988).

19. A. Udagawa, F. Sakurai, and T. Takahashi, J. Appl. Polym. Sci., 42, 1861 (1991).

20. C. Decker, J. Polym. Sci., Part A: Polym. Chem., 30, 913 (1992).

21. N. S. Allen, S. J. Hardy, and A. F. Jacobine, Eur. Polym. J., 26, 1041 (1990).

22. H. Kaczmarek and C. Decker, J. Appl. Polym. Sci., 54, 2147 
(1994).

23. B. S. Chiou and S. A. Khan, Macromolecules, 30, 7322 (1997).

24. J. Paczkowski and D. C. Neckers, Macromolecules, 25, 548 (1992).

25. J. E. Dietz, B. J. Elliott, and N. A. Peppas, Macromolecules, 28, 5163 (1995).

26. B. Li, L. M. Tang, and H. P. Dong, Tsinghua Science and Technology, 5(2), 176 (2000).
27. S. Chatterjee, P. D. Davis, and P. Gottschalk, J. Am. Chem. Soc., 112, 6329 (1990).

28. J. Kabatc, M. Pietrzak, and J. Paczkowski, Macromolecules, 31, 4651 (1998).

29. S. Chatterjee, P. Gottschalk, and P. D. Davis, J. Am. Chem. Soc., 110, 2326 (1988).

30. Z. R. Pan, "Polymer Chemistry", Chemical Industry Press, Beijing, 1986, p 43. 